\title{
PALACIO MULTIUSOS DEL SAR
}

(THE SAR MULTI-PURPOSE PALACE)

J.Miguel Pérez de Arenaza Barcelona, Joaquín Pujol Simón y Xose M. Casabella López, Arquitectos

ESPAÑA

Fecha de recepción: 28-VI-95

\section{RESUMEN}

Se describen, de manera sucinta, las múltiples formas de funcionamiento del Palacio Multiusos del Sar. Desde la idea general del proyecto, que diferencia y complementa espacios para la realización de las distintas actividades lúdicas y deportivas, hasta las diferentes formas de utilización del recinto (espectáculos deportivos, culturales e, incluso, como sede de equipos estables de baloncesto).

Finalmente, se hace hincapié en la solución estructural de las cubiertas, en el funcionamiento de sus instalaciones $y$, de forma especial, en la imagen que un edificio de tales caracteristicas tiene que ofrecer, con el objetivo final de conseguir su perduración.

\section{SUMMARY}

The article offers a brief description of the various forms of functioning of the Sar

Multi-Purpose Palace: from the general idea of the design which distinguishes and complements spaces for the development of different entertainment and sports activities, to the different ways of using the area (sports and culural spectacles and even as head offices of regular basketball teams).

Finally, special emphasis is made on the structural solution of the roof, on the functioning of the installations, and in particular, on the image offered by such a building, with the final aim of achieving a long-lasting life.

\section{Introducción}

El Palacio Multiusos del Sar es un edificio destinado a albergar instalaciones lúdicas y de uso deportivo multitudinario, que se compatibilizarán con una ocupación diaria para la práctica o preparación de deportistas y cursos de mantenimiento de alcance municipal.

Está situado en un valle regado por el río Sar a su paso por Santiago de Compostela, entre el polígono urbano que rodea la Colegiata del Sar. Su privilegiado emplazamiento, al borde del río y proximidad al nuevo cinturón periférico de la población, hacen de él un lugar idóneo, no sólo para la práctica y/o contemplación de espectáculos de diverso tipo, sino que constituye una alternativa ciudadana de esparcimiento y disfrute de la naturaleza, para lo que se ha concebido el tratamiento de un entorno urbanizado como un verdadero parque.

\section{El proyecto}

El edificio emerge sobre un terreno ligeramente inclinado que se ha ido moldeando para formar las dos plataformas dedicadas a aparcamiento, los trazados de los nuevos 


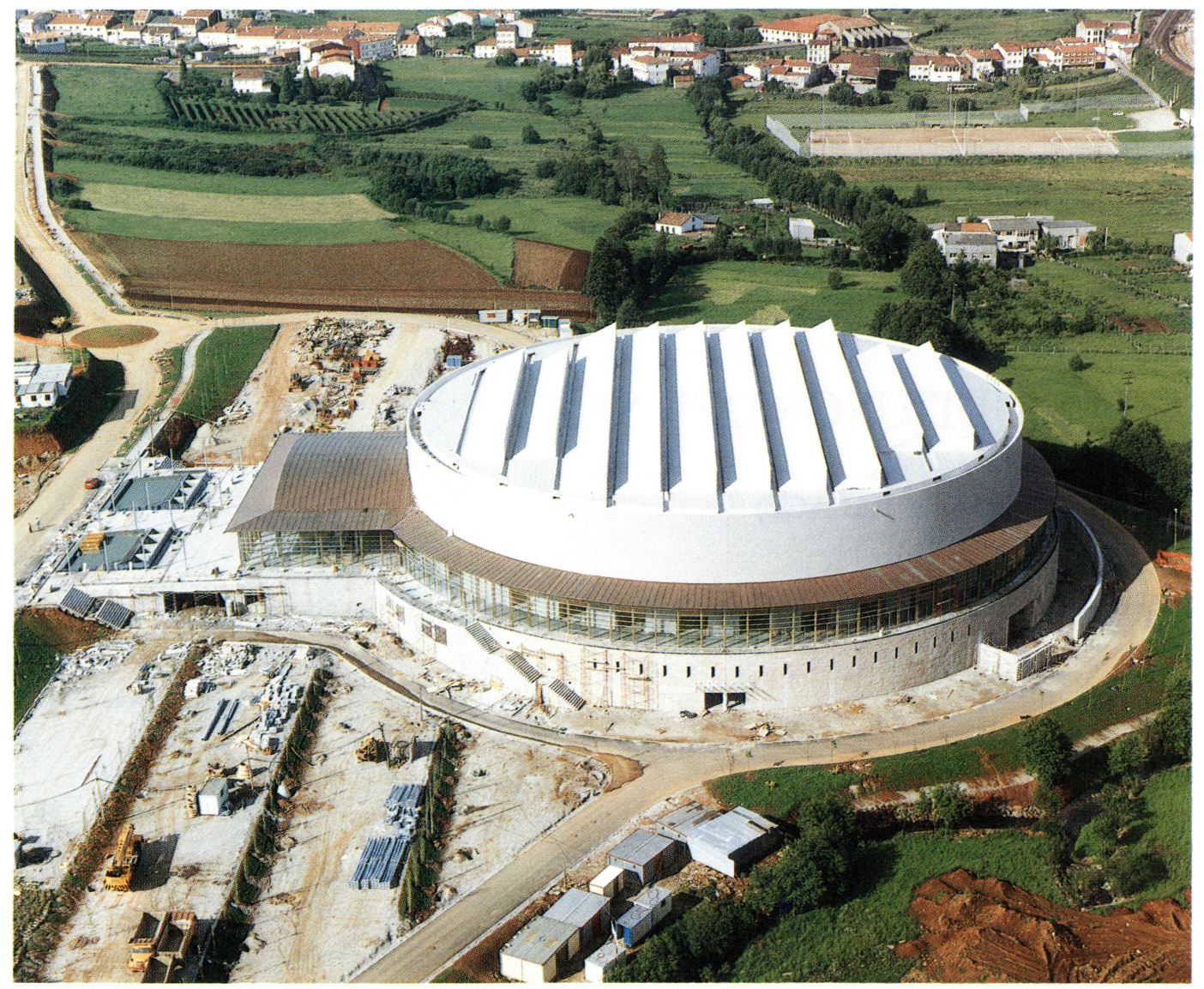

El Palacio Multiusos del Sar.

accesos rodados y los márgenes del río en su totalidad, configuran un nuevo parque fluvial, dotado de recorridos peatonales, carril bici, praderas y arbolado de diferentes especies

El planteamientogeneral del proyecto ha sido el de conseguir unos espacios diversificados lo suficientemente autónomos para que en ellos se puedan compatibilizar usos y actividades dispares y que, al mismo tiempo, estuvieran dispuestas las diferentes piezas que lo integran, de tal forma que permitiesen la mayor flexibilidad de uso de cada una de las dependencias.

El empleo de un riguroso soporte geométrico ha facilitado la definición de cada uno de los componentes básicos de la edificación. Las dos partes principales del Multiusos, el vestíbulo general y la gran sala, surgen de dos tramas geométricas distintas. Para el vestíbulo se ha utilizado una retícula ortogonal y, para la gran sala, otra de trazado circular que concuerda con la anterior, definiendo aquellos aspectos que exigen un trazado ortogonal, comola cubierta, el graderío, etc. La superposición de estas dos tramas geométricas en algunas partes del edificio, lejos de quitarle claridad y rotundidad, lo caracterizan, y hacen que su aspecto adquiera la complejidad que una instalación de las dimensiones y características como la presente pueda ser identificado por sus usuarios y alcanzar la representatividad necesaria en el conjunto de la ciudad y el territorio.

Las dos geometrías complementarias que generan los trazados de la planta del Multiusos, se manifiestan nítidamente en el volumetría general y en la configuración de los espacios interiores, de forma que cada uno de sus componentes pueden ser identificados claramente. La sala principal se define con un cilindro pétreo de $20 \mathrm{~m}$ de altura, coronada por una cubierta compuesta a base de un conjunto de lucernarios de sección triangular. El gran vestíbulo y la galería que circundan la sala se cierran con una cristalera de $6 \mathrm{~m}$ de altura, cubierta por un tejado inclinado de chapa de cobre.

La organización interior del edificio, a pesar de la complejidad exigible para albergar las distintas dependencias, resulta clara e identificable, supeditándose 
a los distintos modos de utilización y funciona miento en el tiempoy enel espacio, tanto para espectáculos deportivos, como culturales (musicales, teatrales,...).

\section{a) Forma de uso para espectáculos deportivos}

En estas situaciones, el Multiusos funciona como un edificio tradicional. El acceso se produce a través del vestíbulo principal, distribuyendo a los espectadores hacia los graderíos de la planta $+0,00$,que rodean la pista de juego en tres de sus lados, adosados al cilindro exterior por medio de la galería perimetral acristalada; a los graderíos del nivel superior se accede mediante cuatro escaleras longitudinales. La cafetería-restaurante está situada en el extremo opuesto a la entrada y se accede a ella por la misma galería. Los aseos del público se sitúan en dos niveles, en los espacios existentes bajo la grada superior.

El público, en este tipo de espectáculos, no tiene acceso a ninguna otra dependencia del edificio, y el control de todas las instalaciones se realiza desde la cabina situada en la parte alta de la sala, sobre la zona de entrada a la misma.

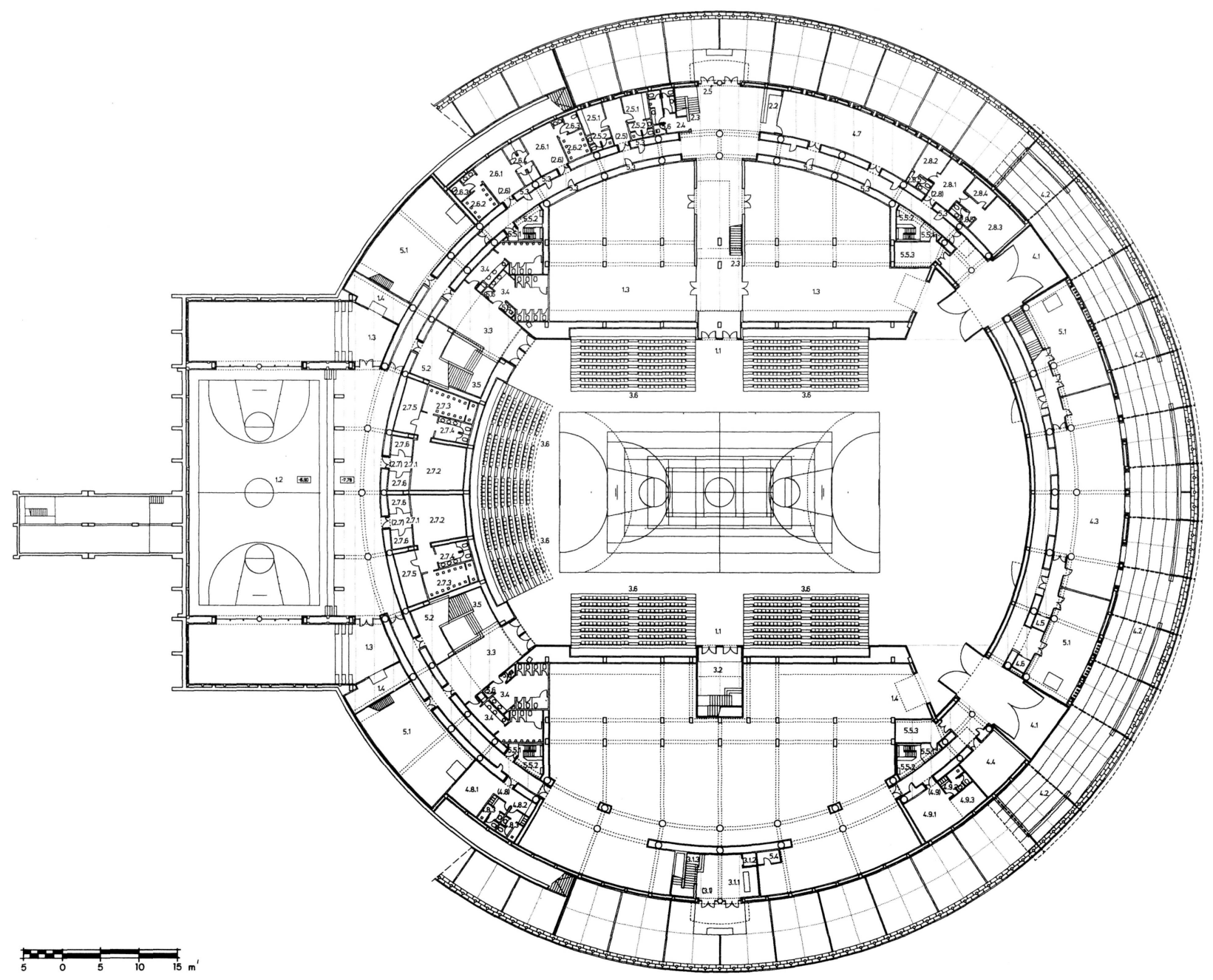

Planta nivel $1(-7,78)$. 


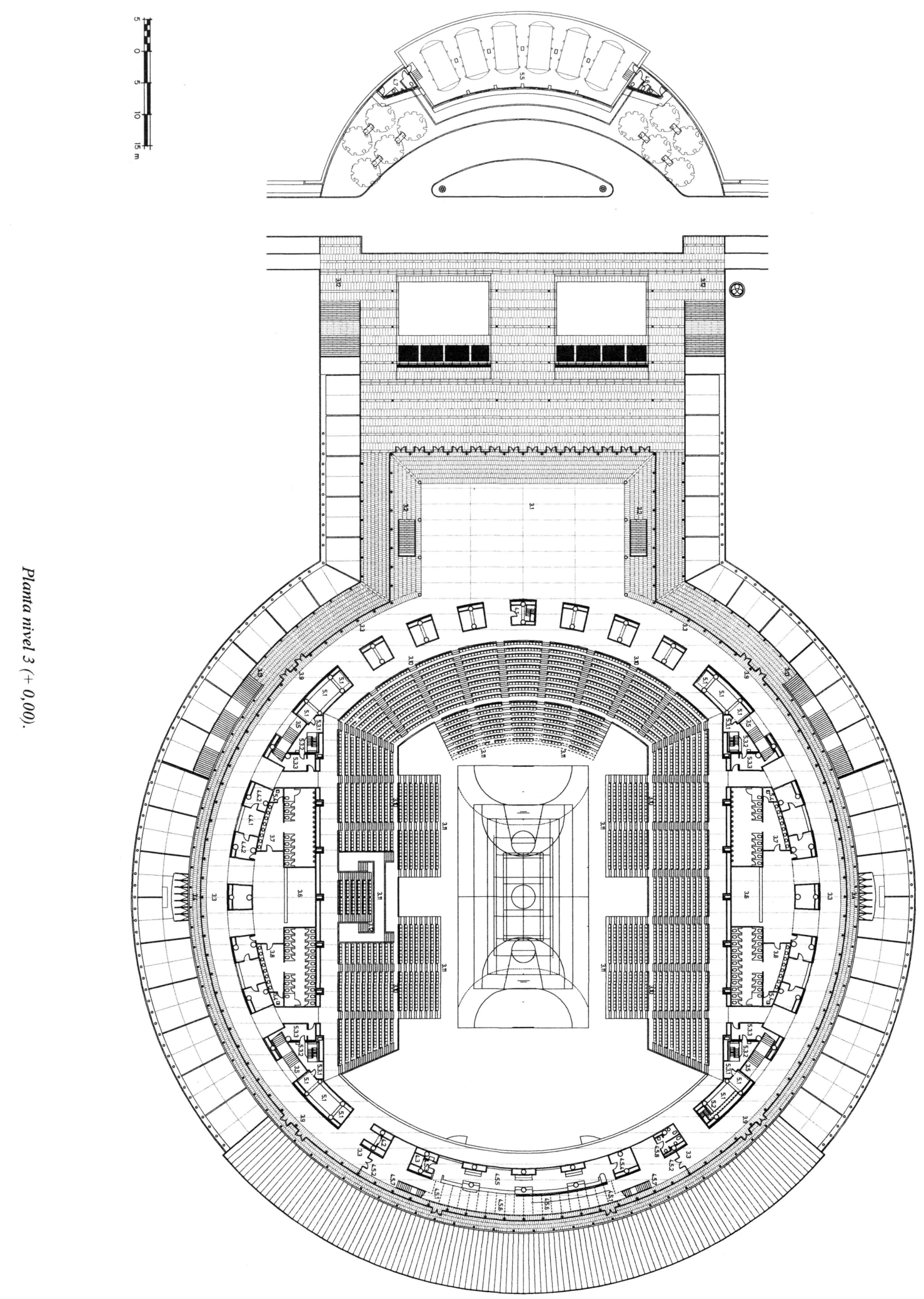

El desalojo se realiza a través de las salidas de emergencia practicadas en la galería y que comunican con un balcón exterior que rodea todo el edificio. Los deportistas tienen acceso por la entrada situada a nivel de'pista, junto a la que se disponen los vestuarios precisos y todas las dependencias necesarias para la práctica deportiva. b) Forma de uso para espectáculos culturales (música, teatro, ópera...)

En estos casos, se ha previsto utilizar la pista de la sala principal recogiendo las gradas retráctiles, para la colocación de sillas en toda su superficie. El escenario se 


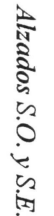
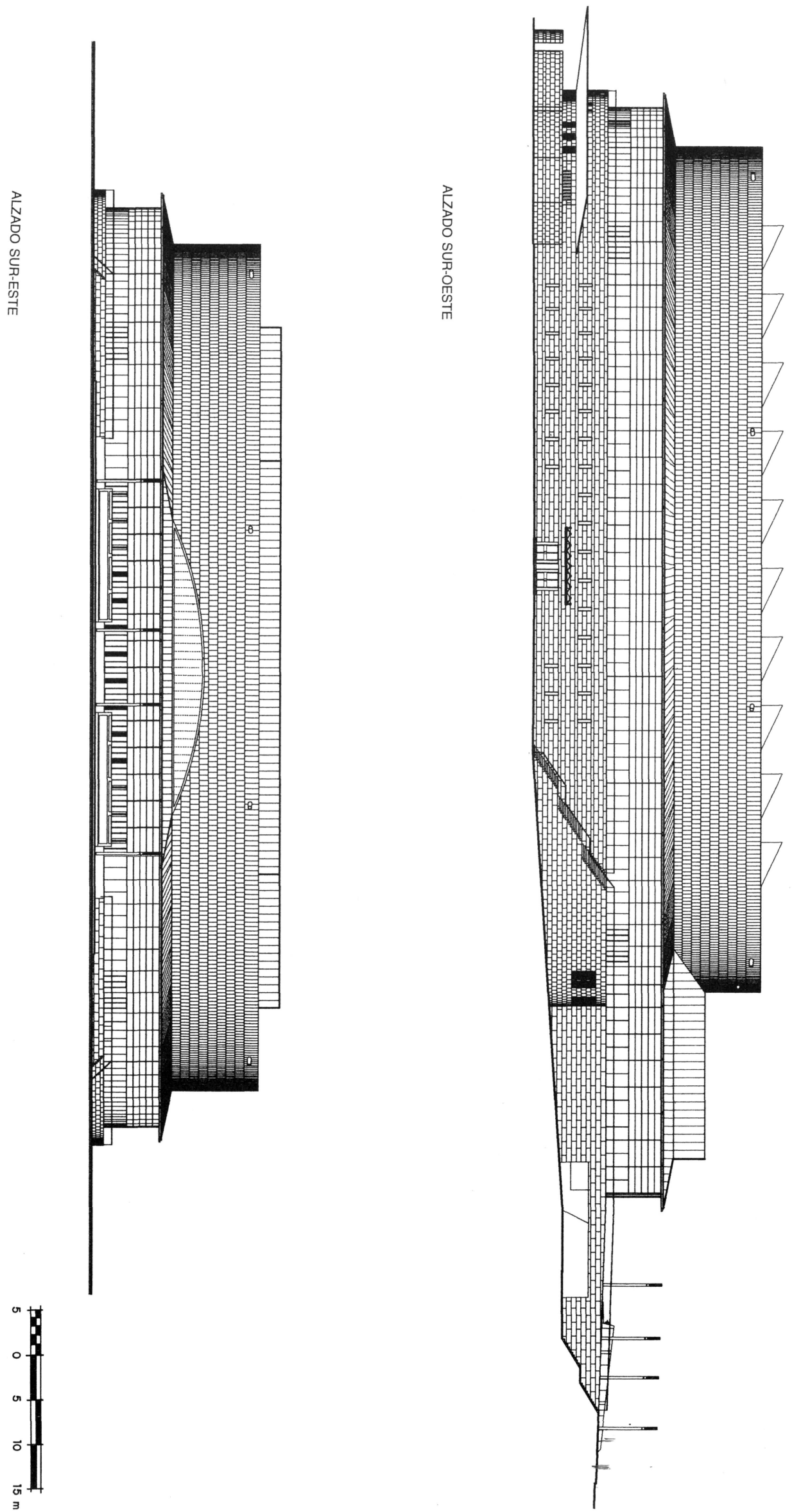

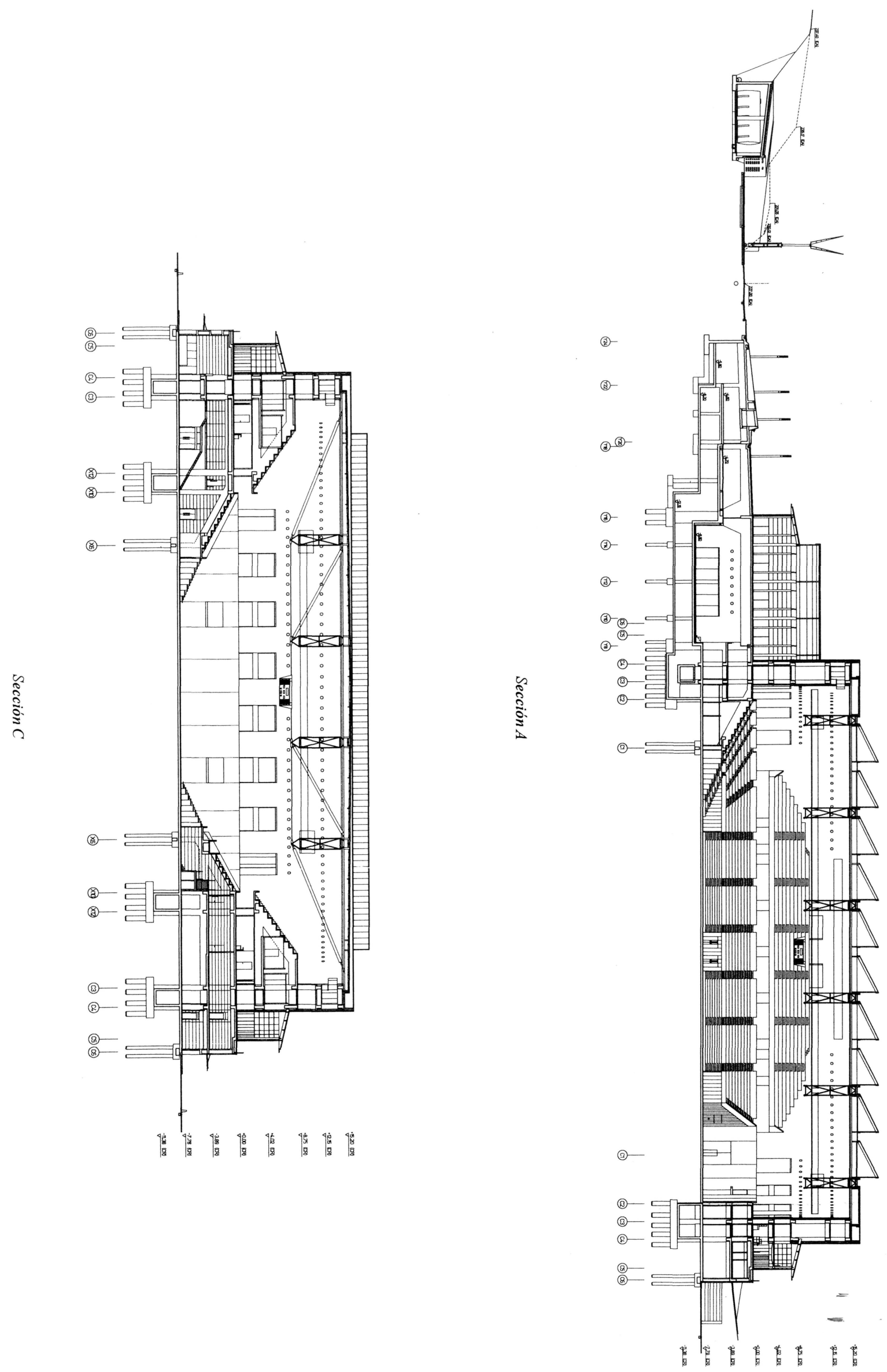
sitúa en el lugar opuesto a la entrada principal, desde el que se podrá conectar, mediante escaleras desmontables, con los camerinos existentes en un nivel intermedio entre la pista y galería de acceso del público.

El acceso del público se realiza de igual modo que en la situación anterior, salvo el que se dirija a la pista, que lo hará por las dos escalinatas que desde el vestíbulo comunican con el nivel de ésta; el desalojo de espectadores se realiza directamente a través de las dos entradas para camiones, situadas próximas al escenario.

c) Funcionamiento como instalaciones para mantenimiento, escuelas deportivas y posible sede de un equipo estable de basket

En estos casos, el acceso se produce solamente a través del vestíbulo de usuarios, situado en el nivel de pista y en un lateral del edificio. Por consiguiente, no se utilizan las gradas de público ni funciona el control general, realizándose todas las operaciones de manejo del mismo desde el mostrador de entrada. Los usuarios tienen acceso a los vestuarios y gimnasios, situados en este nivel de pista y en el existente bajo la grada inferior.

En estas situaciones, se recogerán las gradas retráctiles, disponiendo de todo el espacio de la pista para situar cuatro canchas de baloncesto, separadas mediante cortinas elevables por mecanismos eléctricos.

En caso de existir un equipo estable de baloncesto en la ciudad, se utilizaría la pista de entrenamiento de $7 \mathrm{~m}$ de altura, dispuesta bajo el vestíbulo principal. Su dimensión es equivalente a la de un polideportivo y, anejo al mismo, se han previsto dos pequeños gimnasios de musculación que, en horarios no coincidentes, estarían también disponibles para los usuarios de las escuelas deportivas municipales. Junto a estas instalaciones se han colocado los dos vestuarios para deportistas profesionales, generosamente dimensionados, para que en ellos puedan desarrollarse todas las actividades necesarias.

En el lado opuesto a la entrada de los usuarios de las escuelas deportivas, se ha situado la entrada al palco de autoridades con escalera, ascensor, aseos y salas de descanso propias, desde donde se podrá acceder directamente al nivel de la pista en casos necesarios.

Las dotaciones deportivas se complementan con todas aquellas dependencias necesarias para el correcto funcionamiento del edificio. El almacén general, las oficinas, vestuarios de árbitros, comisaría de policía, catering, etc., se disponen al nivel de pista y se conectan entre sí por un anillo circular que recorre toda la planta.

Para el montaje y desmontaje de espectáculos, se han previsto dos grandes entradas a nivel de pista de vehículos pesados y un porche exterior cubierto y cerrado donde poder estacionar, por ejemplo, los furgones de T.V. o aquellos otros necesarios parala realización de espectáculos.

\section{Estructura}

Uno de los aspectos más singulares del Multiusos del Sar es la solución estructural de las cubiertas de la sala, vestíbulo y galería perimetral, mediante perfiles de madera laminada encolada.

En la galería, se han usado pilares de madera laminada de sección circular; en el vestíbulo, arcos de madera laminada de $30 \mathrm{~m}$ de luz, atirantados con piezas metálicas; en la sala principal, se utilizan vigas cajón de madera laminada,
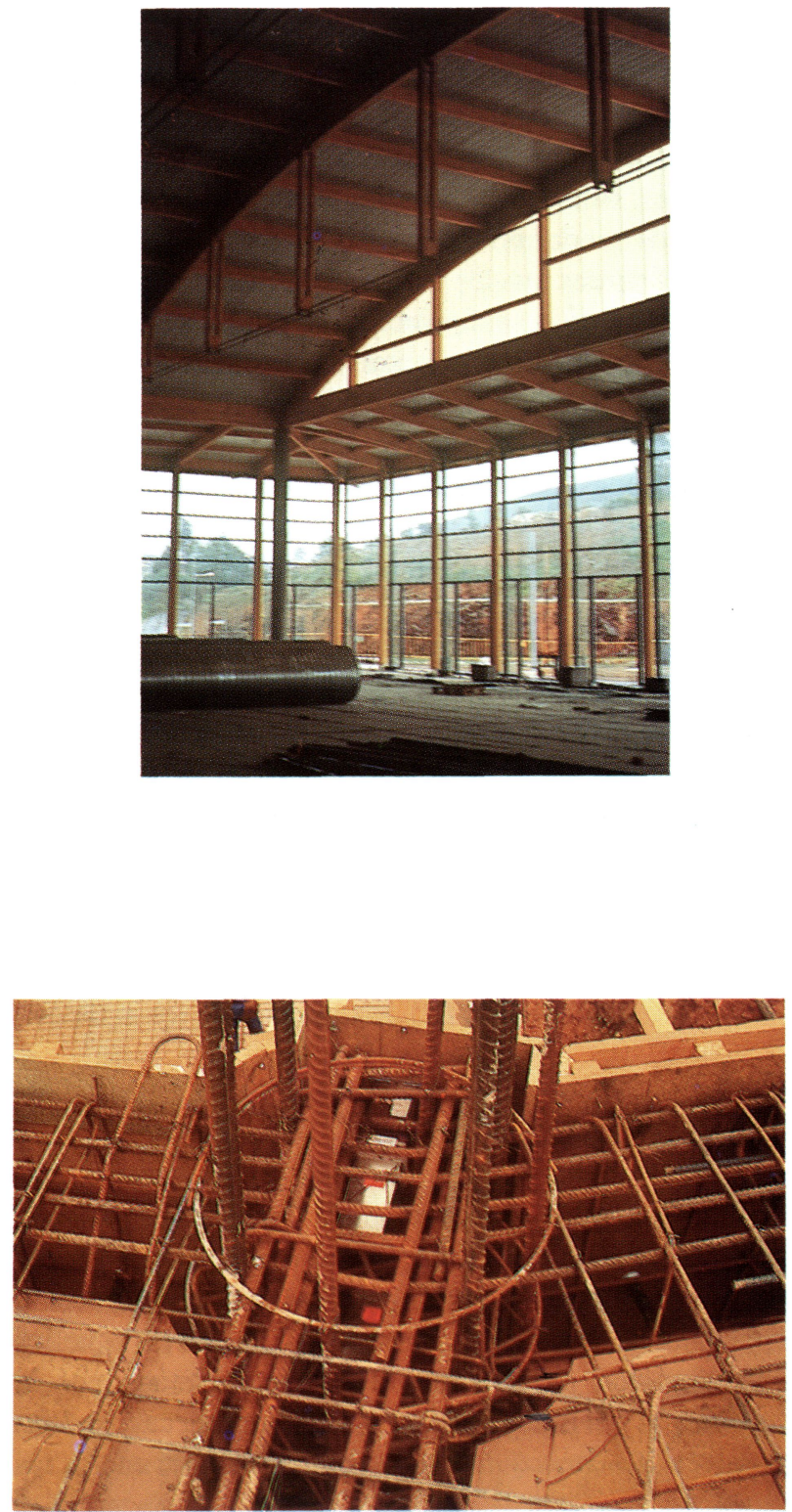
con tirantes y pendolones metálicos que cubren luces de hasta $80 \mathrm{~m}$.

Estas grandes vigas sobre las que se apoyan los lucernarios, también construidos con madera laminada, forman un entramado del que se suspende la cuadrícula de pasarelas accesibles que soportan los elementos de iluminación y las redes de las instalaciones necesarias, a las que de accede desde el anillo perimetral, en la cota superior del edificio.

\section{Instalaciones}

El correcto funcionamiento de una edificación de estas características exige un minucioso estudio de las redes de las instalaciones y la centralización de los equipos necesarios. Bajo la plaza de entrada, se sitúa un verdadero edificio de instalaciones que alberga las dependencias de electricidad, fontanería, climatización y cuadro general de control automatizado.

Climatización: Desde el bloque de instalaciones, se conducen las redes de agua y aire a través de una galería subterránea (compartida para ida y retorno de las conducciones) que alimenta las cuatro climatizadoras principales, situadas en las salas existentes en el nivel de pista, desde donde ascienden verticalmente para dar servicio a los distintos niveles y dependencias del conjunto. La climatización de la sala principal se produce mediante la impulsión por toberas orientables, situadas en la parte superior. El retorno de aire se recoge en el nivel de pista y se conduce por la galería subterránea hasta las climatizaciones. En el resto de las dependencias se dispone de climatizadoras de zona, que resuelven la necesaria programación para las distintas actividades previstas.

Electricidad: Los equipos de transformación y medida, grupo electrógeno y el cuadro general, están situados en el edificio de instalaciones $y$, desde él, se distribuyen las canalizaciones por la galería subterránea, para ascender por los patios previstos al efecto en cuatro zonas de servicio.

Lo mismo ocurre con la instalación de fontanería y con las redes de señalización, megafonía y contraincendios que, en cualquier momento, pueden ser seccionadas por tramos para garantizar el mejor funcionamiento de los equipos.

\section{Imagen exterior del edificio}

El Multiusos del Sar de Santiago de Compostela pretende ser un edificio que permanezca y se mantenga en uso por muchos años. Para ello se han empleado en su construcción materiales de resultados conocidos, huyendo de aquellos cuya duración todavía no ha sido confirmada por la experiencia y el paso del tiempo. Esta actitud, casi podríamos decir, constructivista, está patente en cada uno de los detalles y formas empleadas en la obra. Como ejemplo de ello, basta decir, que no hay paredes enfoscadas ni falsos techos de escayola que oculten y disimulen los aspectos afortunados de la estructura. Todos los paramentos interiores, oestán acabados en ladrillo cara vista o revestidos de plaqueta cerámica. Las conducciones principales de las redes de instalaciones se han dejado vistas y la estructura, tanto de hormigón como de madera, es apreciable en su estado original sin maquillajes ornamentales. La voluntad puesta en que cada unidad de obra se defina formalmente por sí misma, puede tomarse como una actitud de compromisofrente al hecho arquitectónico nada desdeñable, y alcance toda su plenitud en la rotundidad de la forma y textura de las envolventes exteriores, en las que se ha recurrido a los materiales tradicionales de Galicia.

Las dos plantas inferiores, entre el nivel de entrada y la pista de juego, sobresalen en planta seis metros respecto a la envolvente del cuerpo cilíndrico de la sala. Para su cerramiento se han empleado bloques de perpiaño rosa porriño de gran formato, tal y como salen de la cantera, sin más tratamiento, lo que le confiere a este "zócalo" el aspecto de un muro ciclópeo sobre el que se asienta el edificio, como si todo él emergiera del suelo. El tambor que delimita la sala exteriormente está revestido con una fachada ventilada de granito "gris mondariz", colocado a matacorte.

El cerramiento de carpintería de aluminiogris, el vidrio del cerramiento de la galería, la barandilla de acero inoxidable y el cobre de las cubiertas, completan el repertorio de materiales utilizados que, junto a los pavimentos de granito de la plaza de entrada, constituyen un conjunto de notable sobriedad en su aspecto.

Los paramentos de la sala principal y de calentamiento son de ladrillo de cara vista en toda su altura, y los huecos de paso y perforaciones, están cuidadosamente dispuestos en los muros, para conseguir la misma sobriedad que en las fachadas exteriores

El aspecto general de la sala principal, con la estructura de madera laminada y el conjunto de pasarelas metálicas vistas, le confieren a este espacio la solidez y elegancia necesarias para que los usuarios puedan disfrutar de su contemplación y sentirse cómodos en su interior.

En el tratamiento de la urbanización exterior se han seguido los mismos criterios que con el edificio principal, renunciando expresamente al empleo de cualquier artificio en los trazados generales o en los detalles de cada una de las partes.

Las dos grandes áreas de aparcamiento exterior están organizadas en plataformas, separadas por taludes ajardinados, y se comunican entre símediante un túnel practicado bajo la plaza de entrada al edificio. 
Los márgenes del río Sar y los espacios libres se han plantado con césped y árboles autóctonos, para asegurarse del carácter naturalista del entorno, acorde con el conjunto edificado.

El trazado viario asegura las conexiones con las redes de tráfico del resto de la población, para lo que ha sido
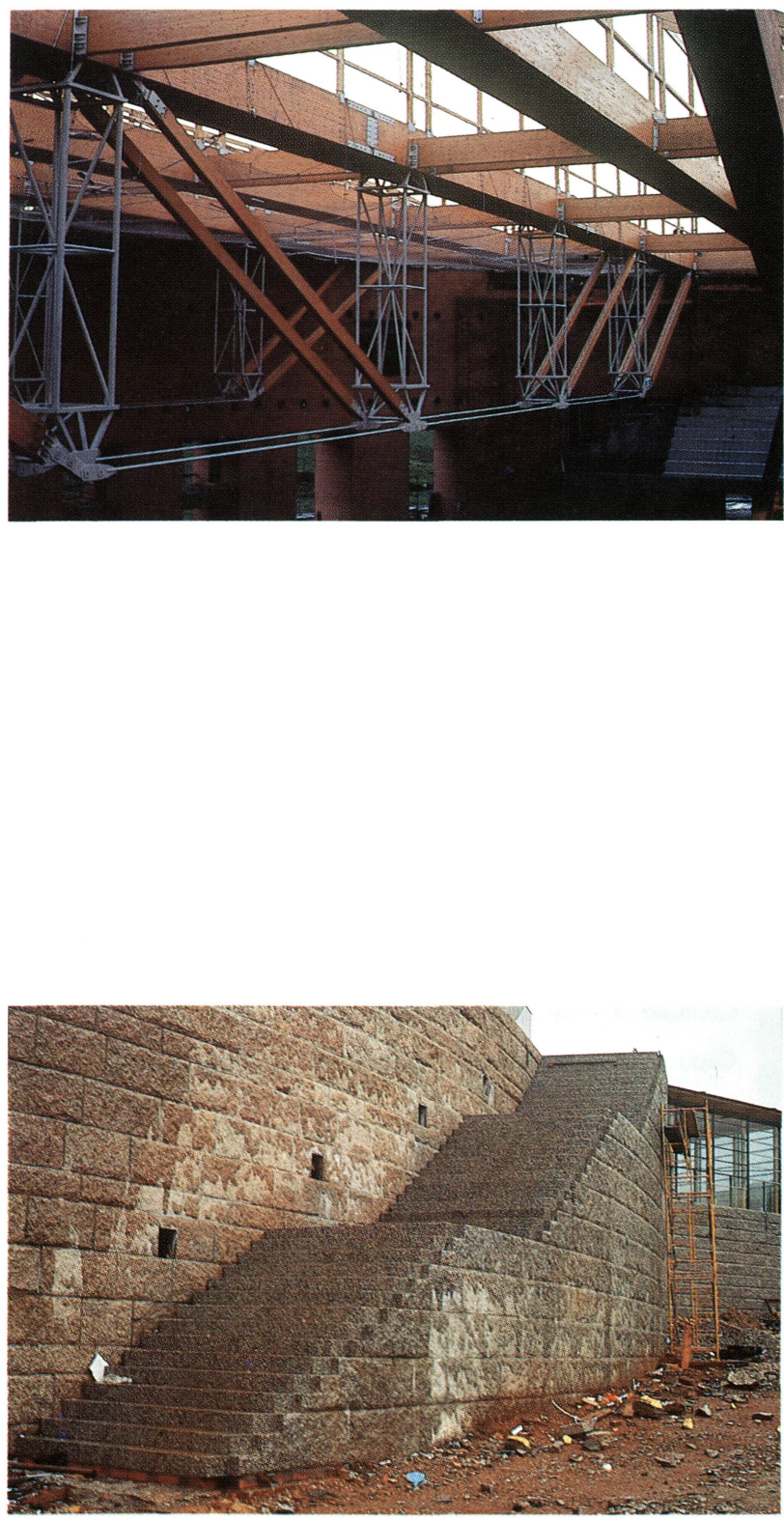

necesaria la construcción de un nuevo puente sobre el río Sar.

Para completar la oferta lúcida y deportiva, se están construyendo actualmente unas piscinas al aire libre en las inmediaciones del Multiusos, y se está redactando el proyecto de un gran parque fluvial que completará las actuaciones previstas en esta zona de Santiago.
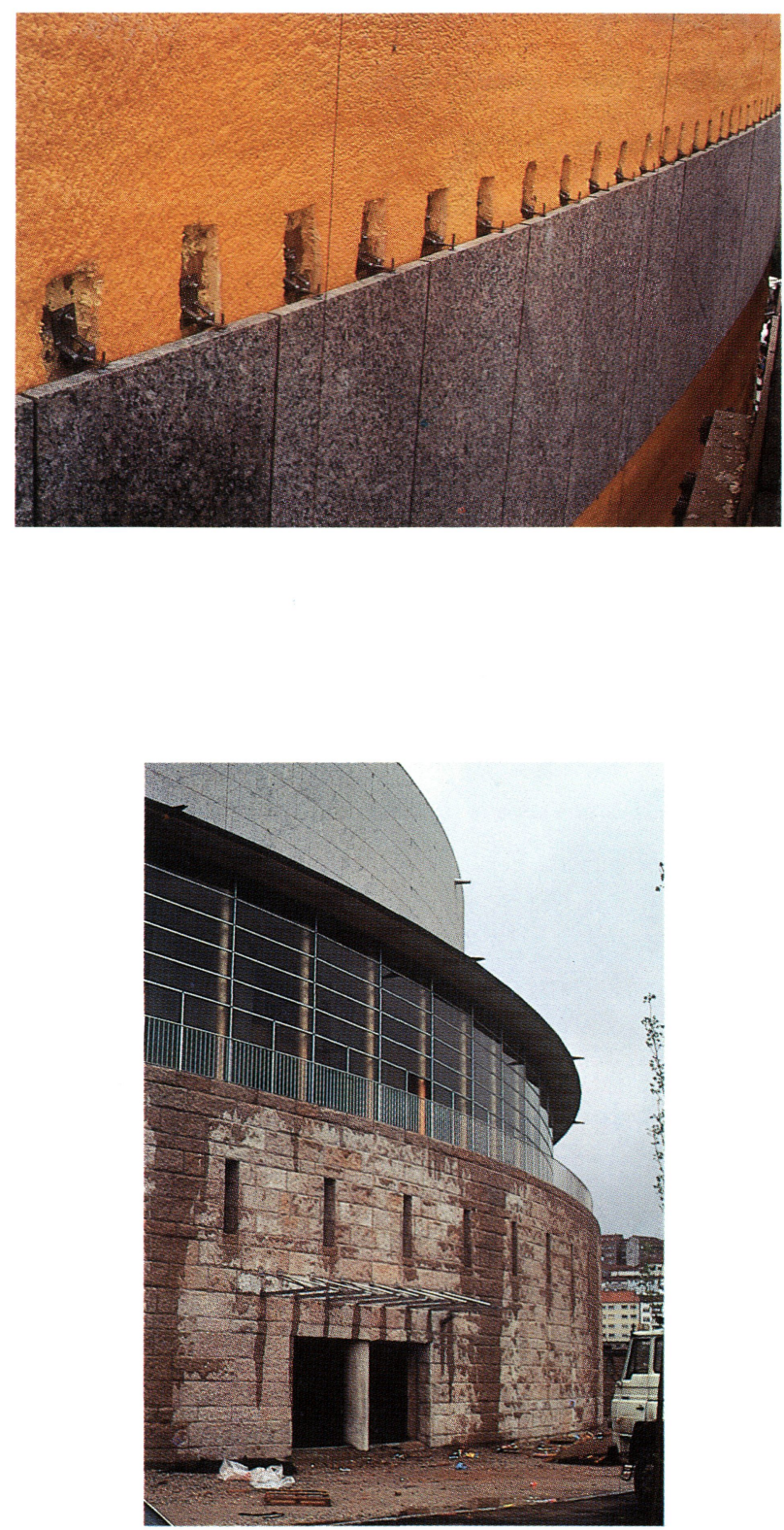
Emplazamiento: Brañas del Sar. Santiago

Propiedad: CONSORCIO DE SANTIAGO

Proy. Arquitectura: ALTIS, Arquitectos

Colaborador Proy.: J. Sabate

Dirección de Obra: ALTIS/J.M. Casabella

Empresa Constructora: CUBIERTAS Y MZOV

Control, Calidad, Instl.: EUROCONSULT

Proy. Instalaciones: O.I.T.

Proy. Estructuras: Juan Solá

Consultor Paisajista: Arquitect. del Paisaje
Pilotaje: PILOTES POSADA

Estrut. madera laminad: CONDEPORT

Cantería y fachada: GRADESA

Cubiertas: CUBIERTAS MUÑOZ

Impermeabilización: TEXSA

Inst. Eléctrica: DAVIÑA

Inst. Climatización: SOCLIMA

Carpintería interior: KEMMLIT

Carpintería exterior: INASUS

Gradas hormigón: PRECÓN

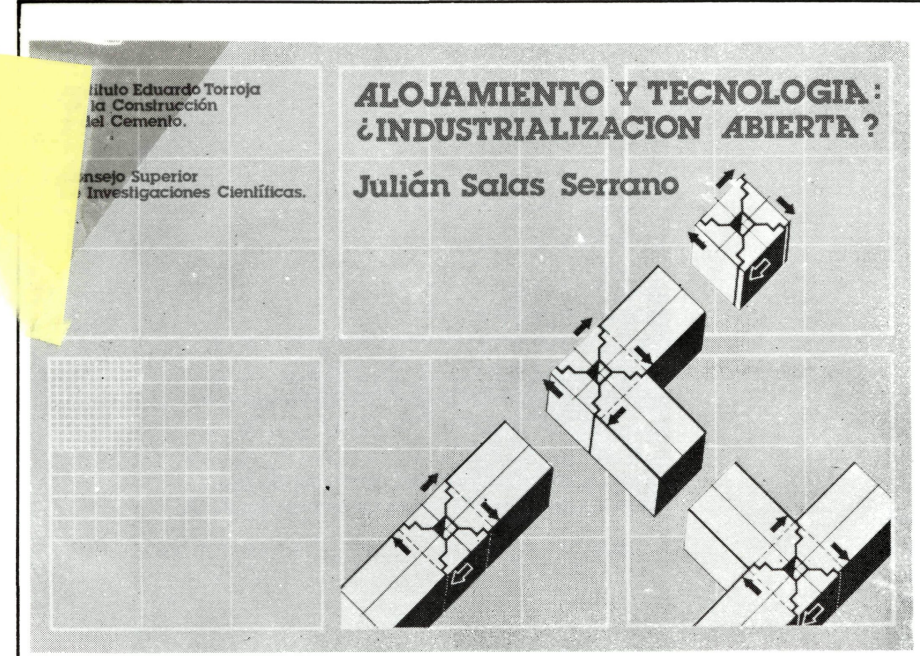

\section{ALOJAMIENTO Y TECNOLOGIA:} ¿INDUSTRIALIZACION ABIERTA?

JULIAN SALAS, ING. IND. (I.E.T.c.c.)

Un volumen de 160 páginas, 109 figuras y 16 tablas. Tamaño $240 \times 168 \mathrm{~mm}$. Encuadernado en rústica. Precios: España, 1.200 ptas; extranjero, 17 \$ USA

\section{SUMARIO}

Prólogo Prof. G. Ciribini.

\section{Introducción}

Capítulo 1.- La industrialización en las proclamas y manifiestos de arquitectura.

Capítulo 2.-¿Réquiem por la construcción industrializada?

Capítulo 3. - Algunos conceptos básicos.

Capítulo 4.- ¿Proyecto tradicional, construcción industrializada?

Capítulo 5.-Componentes.

Capítulo 6. - La coordinación dimensional hoy.

Capítulo 7. - Flexibilidad, intercambiabilidad y catálogos.

Capítulo 8. - Industrialización, normativa y calidad.

Capítulo 9.-Reflexiones finales.

publicación del

INSTITUTO EDUARDO TORROJA 